\title{
Comparison of polytetrafluoroethylene patch aortoplasty and end-to-end anastomosis for coarctation of the aorta
}

\author{
Ronald J. Walhout, MD \\ Jaco C. Lekkerkerker, MD \\ Gordon H. Oron, MD \\ Francois J. Hitchcock, MD, PhD \\ Erik J. Meijboom, MD, PhD \\ Ger B. W. E. Bennink, MD, PhD
}

See related editorial on page 329.

From the Children's Heart Center, Wilhelmina Children's Hospital UMC, Utrecht, The Netherlands.

Received for publication June 18, 2002; revisions requested Aug 20, 2002; revisions received Sept 16, 2002; accepted for publication Oct 8, 2002.

Address for reprints: Ger B. W. E. Bennink, MD, PhD, Wilhelmina Children's Hospital, Department of Cardiology/Cardiac Surgery, University of Utrecht, PO Box 18009 , 3501 CA Utrecht, the Netherlands (E-mail: g.bennink@azu.nl).

J Thorac Cardiovasc Surg 2003;126:521-8

Copyright () 2003 by The American Association for Thoracic Surgery

$0022-5223 / 2003 \$ 30.00+0$

doi:10.1016/S0022-5223(03)00030-8
Objectives: Although aneurysm formation and recoarctation after Dacron patch aortoplasty have been reported on extensively, less is known about these outcomes after polytetrafluoroethylene patch repair, which was compared with resection and end-to-end anastomosis in this study.

Methods: Two hundred sixty-two children had surgical repair of coarctation of the aorta by means of either resection and end-to-end anastomosis $(n=137$; mean age, $1.85 \pm 3.1$ years $)$ or polytetrafluoroethylene patch aortoplasty $(\mathrm{n}=118$; mean age, $1.09 \pm 1.9$ years) during a 28-year period. Coarctation was isolated in $109(41.6 \%)$, associated with ventricular septal defect in 77 (29.4\%), and associated with complex intracardiac anomalies in 76 (29.0\%) patients. Follow-up ranged from 2 days to 29.3 years (median, 11.9 years). Seven patients were lost to follow-up. Kaplan-Meier survival curves were estimated, and multivariable Cox regression analysis was performed for several outcome variables.

Results: Mortality was $8.2 \%$ and was associated with intracardiac pathology in all cases. Recoarctation occurred in 53 patients, 23 after resection and anastomosis and 30 after patch repair, not differing statistically $(P=.4$, log-rank test). Aneurysm formation occurred in 8 patients after patch repair that included ridge resection in 7 of the 8 patients. Late hypertension occurred in less patients $(\mathrm{n}=3)$ after resection and anastomosis than after patch repair $(\mathrm{n}=8)(P<.03)$. Arch hypoplasia $(P<$ $.01)$ and age less than 1 month $(P<.001)$ were found to be independent risk factors for recoarctation.

Conclusions: Polytetrafluoroethylene patch repair including coarctation ridge resection was found to be a risk factor for aneurysm formation and late hypertension. Arch hypoplasia and young age must be considered to predispose to recoarctation.

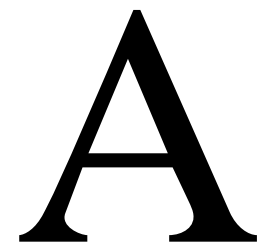

neurysm formation after Dacron patch aortoplasty for coarctation of the aorta has been reported on extensively, in as much as $51 \%$ of patients. ${ }^{1}$ However, aneurysm incidence after repair with polytetrafluoroethylene (PTFE) appears to be comparable with that after other techniques. ${ }^{2}$ Among a variety of surgical techniques, we have continued to perform patch aortoplasty with PTFE as patch material in the recent past. The objectives of this retrospective review were 3 -fold. Our first intent was to evaluate the immediate results and long-term follow-up regarding mortality, recoarctation, aneurysm formation, and late hypertension after coarctation repair in all age groups with resection and end-to-end anastomosis (RETE) and patch angioplasty. The second goal was to compare those results for both surgical techniques to identify the ideal form of surgical management or to specify indications for these techniques. The third and final objective was 
TABLE 1. Associated cardiovascular anomalies and noncardiac anomaly syndromes

\begin{tabular}{lc}
\hline & No. (rate) \\
\hline Associated cardiovascular anomalies & \\
Group 1: Isolated coarctation & $111(41.3 \%)$ \\
Group 2: Coarctation with VSD & $80(29.7 \%)$ \\
Perimembranous & $45(56.3 \%)$ \\
Muscular & $18(22.5 \%)$ \\
Outlet & $9(11.3 \%)$ \\
Multiple & $5(6.3 \%)$ \\
Inlet & $1(1.3 \%)$ \\
Apical & $1(1.3 \%)$ \\
Doubly committed & $1(1.3 \%)$ \\
Group 3: Coarctation with complex cardiac anomaly & $78(29.0 \%)$ \\
Aortic stenosis & 25 \\
+ VSD & 3 \\
Mitral valve anomaly & 18 \\
Transposition of great arteries & 6 \\
+ VSD & 9 \\
AVSD & 5 \\
Double-outlet right ventricle & 1 \\
+ VSD & 4 \\
Single ventricle & 2 \\
+ VSD & 2 \\
Double-outlet left ventricle & 1 \\
Unspecified & 2 \\
Noncardiac anomaly syndromes & 2 \\
Multiple congenital malformations, unspecified & 4 \\
Down syndrome & 4 \\
DiGeorge syndrome & 3 \\
Schizis & 2 \\
VATERR association & 2 \\
Turner syndrome & 1 \\
Microphtalmia, micrognatia & 1 \\
Brown syndrome & 1 \\
Williams-Beuren syndrome & 1 \\
Multiple skeletal malformations, unspecified \\
CHARGE association & 1 \\
\hline VD Ventricular sental & \\
\hline
\end{tabular}

$V S D$, Ventricular septal defect; AVSD, atrioventricular septal defect; VATERR, vertebral defects, imperforate anus, tracheoesophageal fistula, and radial and renal dysplasia; CHARGE, coloboma, heart disease, atresia choanae, retarded growth and development and/or central nervous system anomalies, genital hypoplasia, and ear anomalies and/or deafness.

to identify risk factors for various outcomes on which our surgical management can be based.

\section{Patients and Methods \\ Patients}

Between 1973 and 2000, 262 children had surgical repair of coarctation of the aorta by means of either RETE or PTFE patch aortoplasty. Of the total, 163 were boys and 99 were girls. Diagnoses included isolated coarctation of the aorta in $109(42 \%)$ of 262 patients (group 1), coarctation of the aorta and ventricular septal defect in 77 (29\%) of 262 patients (group 2), and coarctation of the aorta with complex intracardiac anomaly in $76(29 \%)$ of 262 patients (group 3). Associated cardiovascular anomalies and noncardiac anomaly syndromes are summarized in Table 1 . The mean age at the time of surgical intervention was $1.85 \pm 3.1$ years for
$\operatorname{RETE}(\mathrm{n}=137)$ and $1.09 \pm 1.9$ years for patch angioplasty $(\mathrm{n}=$ 117). Percentages of female patients were $39 \%$ (55/141) for RETE and $64 \%$ (44/121) for patch angioplasty. Percentages of pathology for groups 2 and 3 were $31 \%(44 / 141)$ and 25\% (35/141) for RETE and 27\% (33/121) and 34\% (41/121) for patch angioplasty, respectively. Associated isthmus hypoplasia was defined as an isthmus diameter of less than $40 \%$ of the diameter of the ascending aorta. ${ }^{3}$ Arch hypoplasia was defined as a proximal or distal transverse arch diameter of less than $60 \%$ or $50 \%$, respectively, of the diameter of the ascending aorta. ${ }^{3}$ Isthmus hypoplasia, arch hypoplasia, or both, was present in 25 (23\%) of 109 patients in group $1,36(47 \%)$ of 77 patients in group 2, and $23(30 \%)$ of 76 patients in group 3. Age at presentation ranged from birth to 15.4 years (median, 41 days) in group 1, from birth to 12.0 years (median, 21 days) in group 2 , and from birth to 11.0 years (median, 22 days) in group 3. Method of diagnosis included blood pressure measurement and echocardiography in all patients. Additionally, catheterization was performed in patients in group 3 and in patients in whom echocardiography was not conclusive.

\section{Surgical Management}

During the study period, 2 surgeons performed the vast majority of surgical procedures. Repair-operative approach was a left thoracotomy in group 1 and in patients with a staged repair in groups 2 and 3. Median sternotomy was the approach for complete repair in groups 2 and 3. A 1-stage repair was undertaken in $16(10 \%)$ of 153 patients in groups 2 and 3. The initial procedure in all other patients consisted of aortic arch repair; close follow-up with echocardiographic monitoring indicated the need and timing of a subsequent procedure. Repair consisted of RETE in 137 (52\%) of 262 patients and PTFE patch aortoplasty in 125 (48\%) of 262 patients. A combination of both techniques in one procedure was performed in $4(1.5 \%)$ of 262 patients. This combined technique was performed in patients in whom a primarily performed RETE did not relieve the aortic gradient satisfactorily. Patch aortoplasty was performed subsequently within one session. These 4 procedures were considered primary failures of RETE. The technique of repair that was used varied according to the surgeon's preferences predominantly. The coarctation ridge was excised in the performance of patch aortoplasty until 1991. All surgical procedures until the mid-1980s were performed with continuous 6-0 polypropylene suture, whereas continuous 6-0 and 7-0 monofilament nonabsorbable sutures were used thereafter. Cardiopulmonary bypass, performed with circulatory arrest and cooling, was restricted to complete repair in groups 2 and 3.

The immediate results of surgical intervention were considered satisfactory if a pulsatile flow in the descending aorta was registered by means of palpation after the operation and the resultant pressure gradient between the upper and lower limbs was less than $20 \mathrm{~mm} \mathrm{Hg}$.

\section{Follow-up}

The length of follow-up ranged from 2 days to 29.3 years (median, 11.9 years). Seven patients were lost to follow-up: 4 patients after RETE and 3 after patch angioplasty. Follow-up was limited by death in 26 patients. Follow-up ranged from 1 to 10 years in 115 (44\%) of 262 patients and from 10 to 20 years in 102 (39\% of 262) patients and was greater than 20 years in 45 (17\%) of 262 patients. 


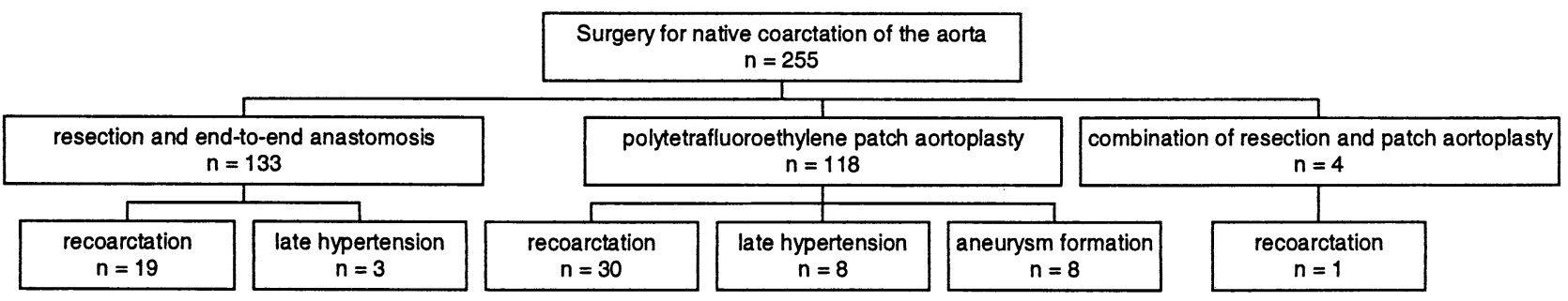

Figure 1. Flow diagram of all patients $(n=255)$ managed in a 28 -year period. Patients lost to follow-up $(n=7)$ are not included.

Follow-up included clinical evaluation every 3 months in the first year after intervention and yearly thereafter. Arm and leg cuff pressures were registered, and chest radiography and 2-dimensional continuous-wave echocardiographic Doppler ultrasound studies performed. Follow-up catheterization and angiography were performed in patients in whom aneurysm formation or recoarctation was suspected. An aneurysm was defined as an aortic ratio of greater than 1.5 , measuring aortic diameters at the coarctation repair site and thoracic aorta at the level of the diaphragm. A gradient of $20 \mathrm{~mm} \mathrm{Hg}$ and a registered continuation of flow in diastole in echocardiographic Doppler ultrasound studies or blood pressure gradients between the upper and lower extremities exceeding $20 \mathrm{~mm} \mathrm{Hg}$ were considered to correspond with recoarctation, requiring reintervention. Magnetic resonance imaging was performed in patients suspected of having aneurysm formation. Recoarctation was treated with repeat surgery or BA after additional angiography.

\section{Statistical Methods}

Kaplan-Meier survival curves were estimated to determine intervention-free probabilities for various groups. Cumulative probabilities in these groups were compared against guidelines by using the log-rank test. Multivariable Cox regression analyses were performed for the various outcomes for which sufficient events were encountered. Potential risk factors in these analyses included era (1973-1987 vs 1988-2000), age (<1 month, 1 month to 1 year, or $>1$ year), type of repair (PTFE patch aortoplasty vs RETE), and aortic arch hypoplasia, isthmus hypoplasia, or both.

\section{Results}

Follow-up of all patients is summarized in Figure 1.

\section{Immediate Results}

Hospital stay varied from 6 to 22 days (median, 11 days). Complications not resulting in death were encountered after $17(6.7 \%)$ of 255 procedures and included persistent hypertension in $6(2.3 \%)$ of 255 patients. In 2 of these patients, this persistent hypertension could not be treated satisfactorily at long-term follow-up, persistent hypertension thereby transferring to late hypertension. False aneurysm formation (2 patients), bleeding, arrhythmia, chylothorax (2 patients), stroke ( 2 patients), atelectasis, and thrombus formation in the left atrium were encountered in the rest of these patients.
TABLE 2. Mortality specified $(n=21 / 255)$

\begin{tabular}{lr}
\hline Primary coarctation repair & \\
Postoperatively, simultaneous correction of VSD & 5 \\
Postoperatively, simultaneous aortic valvuloplasty & 2 \\
Unrelated cardiac surgery, postoperatively & 9 \\
Follow-up & \\
Arrhythmia & 1 \\
Pneumonia & 2 \\
Sepsis & 1 \\
Secondary coarctation repair & 1 \\
Total & 21
\end{tabular}

VSD, Ventricular septal defect.

\section{Mortality}

Mortality is specified in Table 2. Overall mortality was 21 (8.2\%) of 255 patients. Seven patients died of postoperative complications after primary repair of coarctation. The procedure used was RETE in 3 of 7 patients and patch aortoplasty in 4 of 7 patients. Kaplan-Meier analysis for survival was performed, differentiating groups 1, 2, and 3. The cumulative survival probability at 10 years' follow-up was $96.8 \% \pm 1.8 \%$ for patients in group $1,87.0 \% \pm 4.4 \%$ in group 2 , and $80.6 \% \pm 4.9 \%$ in group 3. Log-rank testing revealed a significant difference between these groups regarding mortality $(P=.001$, Figure 2$)$.

\section{Recoarctation}

Recoarctation occurred in $53(21 \%)$ of 255 patients, of whom $23(43 \%)$ of 53 had an RETE and $30(57 \%)$ of 53 had a patch graft angioplasty. Log-rank testing revealed no significant difference between techniques regarding reintervention for recoarctation $(P=.4$, Figure 3$)$. Transverse arch hypoplasia was present in $32(12.5 \%)$ of 255 patients, isthmus hypoplasia in $36(14.1 \%)$ of 255 patients, and both conditions in $18(7.1 \%)$ of 255 patients. Of both conditions, arch hypoplasia was the only one for which a significant difference in reintervention was found $(P=.030$, log-rank test; Figure 4). Repair was performed at age less than 1 month in 105 (41\%) of 255 patients, between 1 month and 1 year of age in 75 (29\%) of 255 patients, and after 1 year of age in $75(29 \%)$ of 255 patients. Recoarctation rates were 


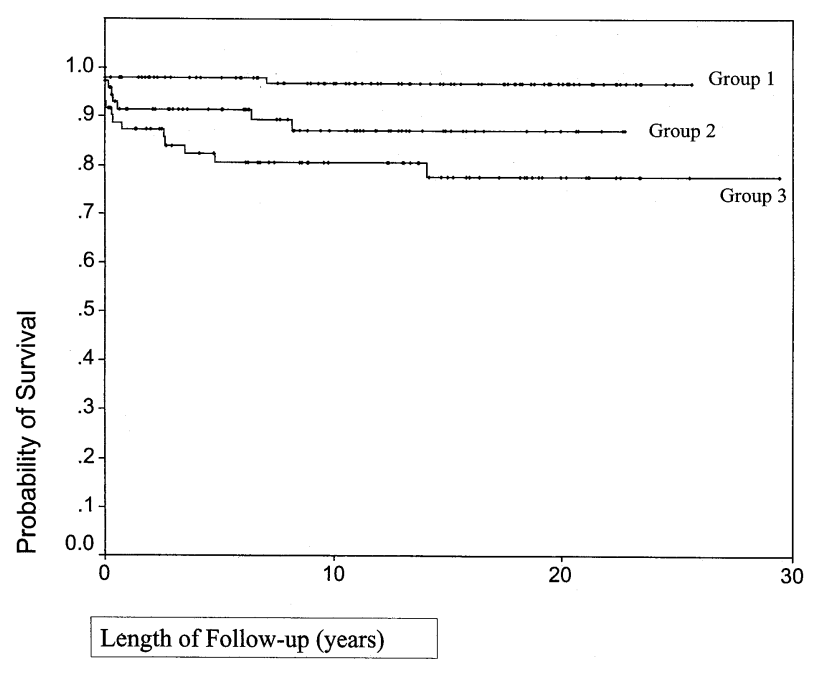

Figure 2. Kaplan-Meier curves for the probability of survival in patients with native coarctation managed surgically in different groups with isolated coarctation, associated ventricular septal defect, and associated intracardiac pathology. The numbers of patients available for follow-up at 5-year intervals are depicted below the graphs.

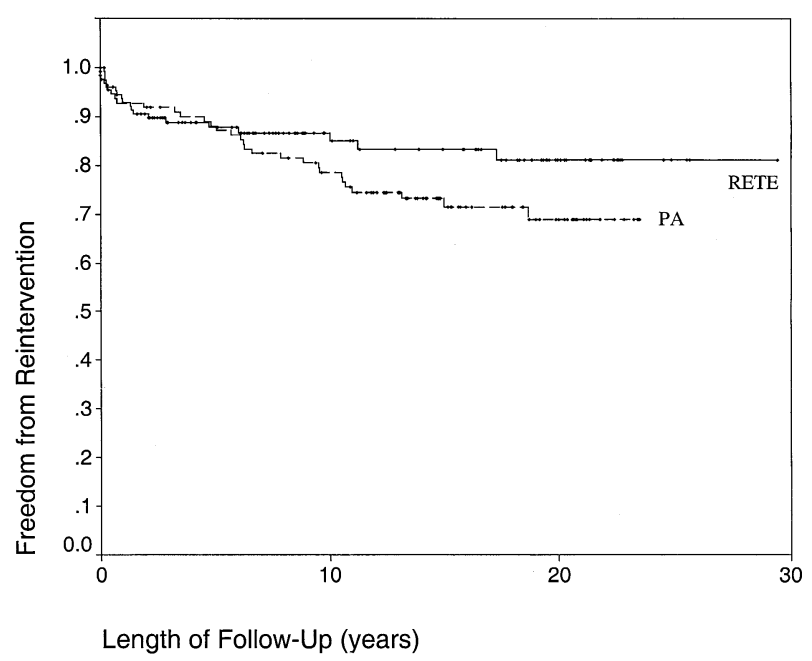

Figure 3. Kaplan-Meier curves for probability of freedom from reintervention in patients with native coarctation managed with RETE ( $n=133$ ) and patch graft angioplasty $(P A, n=118)$. The numbers of patients available for follow-up at 5-year intervals are depicted below the graphs.

35 of 105,11 of 75 , and 8 of 75 patients, respectively. A significant difference was found between these age groups regarding recoarctation $(P<.001, \log$-rank test; Figure 5). Reintervention was performed in all patients with recoarctation. Two patients received RETE, 18 received patch angioplasty, and 32 were treated with BA. Recoarctation occurred in 2 patients who had been undergone operations,

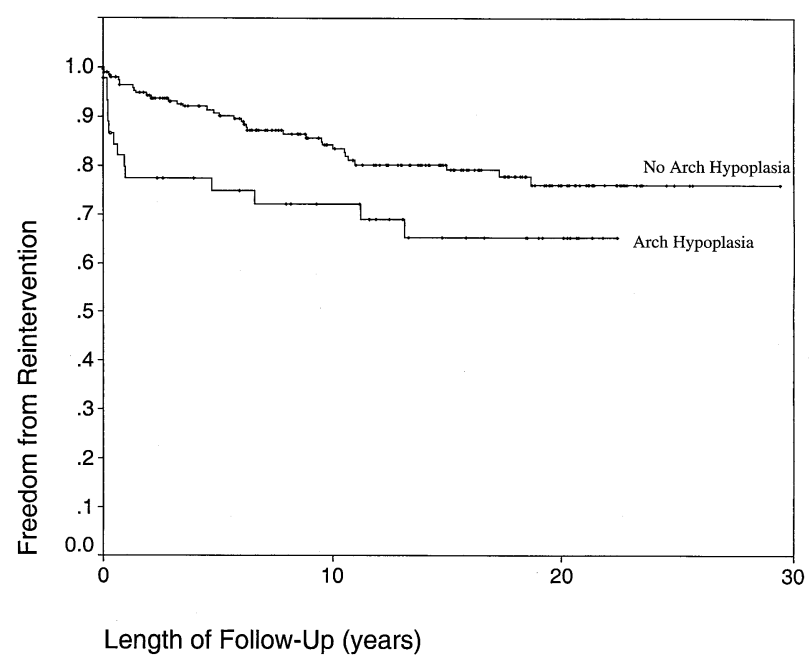

Figure 4. Kaplan-Meier curves for probability of freedom from reintervention in patients with surgically corrected native coarctation with (lower plot, $n=50$ ) and without (upper plot, $n=205$ ) associated arch hypoplasia. The numbers of patients available for follow-up at 5-year intervals are depicted below the graphs.

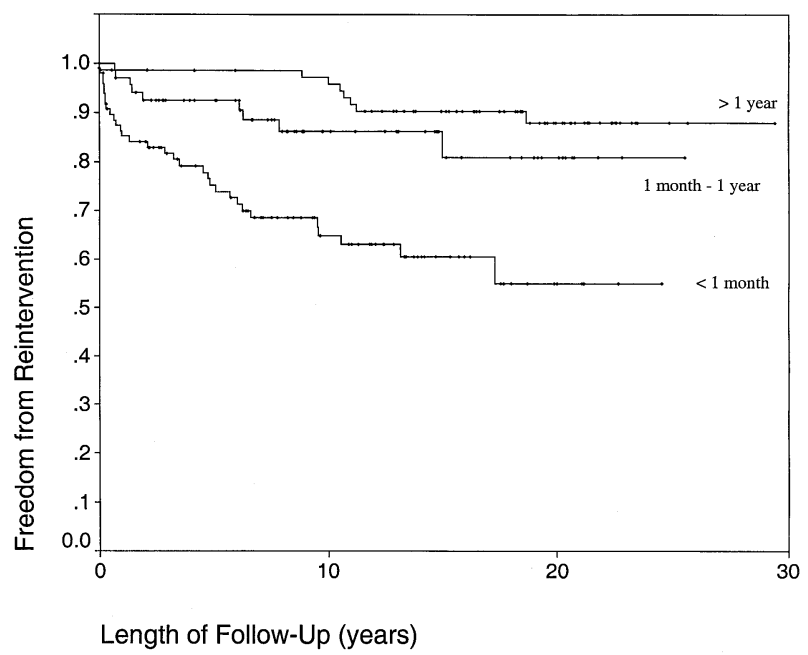

Figure 5. Kaplan-Meier curves for probability of freedom from reintervention in patients with surgically corrected native coarctation younger than 1 month (lower plot, $n=105$ ), between 1 month and 1 year (middle plot, $\mathrm{n}=75$ ) and older than 1 year (upper plot, $\mathbf{n}=75$ ) of age. The numbers of patients available for follow-up at 5-year intervals are depicted below the graphs.

and these patients underwent secondary BA and RETE. Age less than 1 month at repair and the presence of transverse arch hypoplasia were the only predictors for recoarctation in multivariable Cox regression analysis. A relative risk of recoarctation for patients less than 1 month of age compared with patients greater than 1 year of age of 6.3 (95\% confidence interval, 2.8-14; $P<.001$ ) was found. No difference 
between patients from 1 month to 1 year of age compared with patients greater than 1 year of age was found. The relative risk associated with arch hypoplasia was $2.4(95 \%$ confidence interval, $1.34 .5 ; P=.006)$. On the contrary, the type of repair, the presence of isthmus hypoplasia, the era of repair (1971-1987 vs 2988-2000) and associated cardiac pathology were not significant risk factors.

\section{Late Hypertension}

Late hypertension, defined as blood pressure exceeding $150 / 90 \mathrm{~mm} \mathrm{Hg}$ in the right arm, measured at regular follow-up assessment was encountered in 11 (4.3\%) of 255 patients. Late hypertension was encountered in $5(2.8 \%)$ of 176 patients younger than 1 year of age and in $6(8.0 \%)$ of 75 patients older than 1 year of age. The preceding type of coarctation repair had been RETE in 3 (27\%) of 11 patients and patch aortoplasty in $8(73 \%)$ of 11 patient. All of these 11 patients needed medication to control this hypertension. Recoarctation had been encountered in $6(55 \%)$ of 11 patients with late hypertension at any time during follow-up at the time of this review. Hypertension persisted after management of recoarctation in these 6 patients. Age and late hypertension were not found to be related. Patch aortoplasty was associated with a higher rate of late hypertension $(P<$ .03 , log-rank test).

\section{Aneurysm Formation}

Aneurysm formation was encountered in $8(3.1 \%)$ of 255 patients, all after patch aortoplasty (Figure 6). The interval to aneurysm formation varied from 4 days to 18.6 years (median, 12.3 years). The actuarial 15 -year probability of freedom from aneurysm formation after patch aortoplasty was found to be $93 \% \pm 3.1 \%$. The aneurysm that developed within 4 days after surgical intervention was identified to be a false aneurysm. All other aneurysms developed opposite the patch along the medial aspect of the aorta. All these aneurysms developed after procedures involving coarctation ridge resection performed before 1991. Transverse arch hypoplasia was present in 1 of these patients, and both arch and isthmus hypoplasia were present in 2 of these patients. Patients in whom aneurysm formation was encountered underwent successful aneurysm resection and patch graft interpositioning. Neither age nor transverse arch-isthmus hypoplasia were predictors of aneurysm formation.

\section{Discussion}

Immediate results are satisfactory in this series. Few complications were encountered, and early mortality occurred in $7(2.7 \%)$ of 262 patients after primary coarctation repair. The presence of associated cardiac lesions was related to postoperative death in this series. Similar findings have been reported by several authors. ${ }^{4-6}$ Reported actuarial sur-

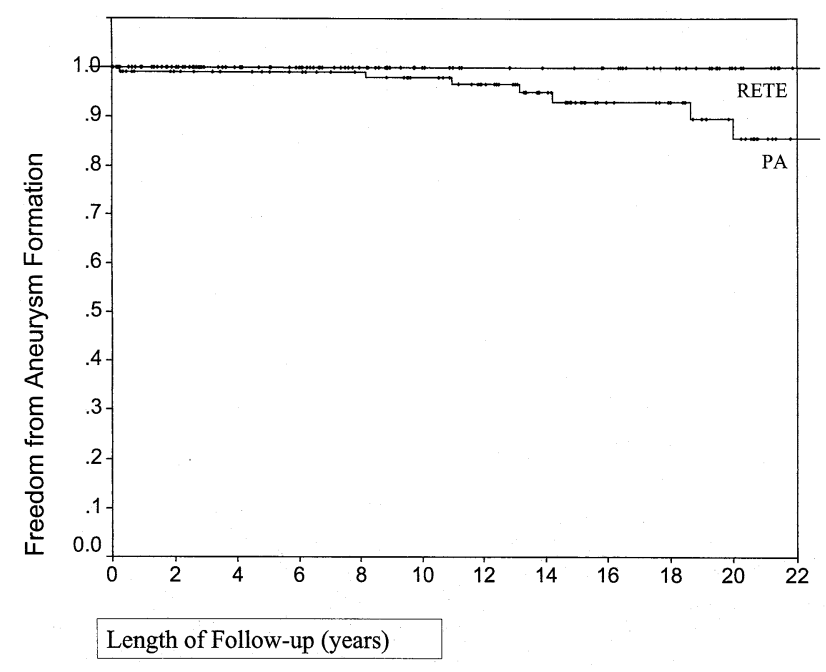

Figure 6. Kaplan-Meier curves for probability of freedom from aneurysm formation in patients with native coarctation managed with RETE ( $n=133$ ) and patch graft angioplasty $(P A, n=118)$. Length of follow-up is truncated at 22 years with 5 and 7 patients at risk for RETE and patch repair, respectively. The numbers of patients available for follow-up at 5-year intervals are depicted below the graphs.

vival probabilities at 5 years range from $80 \%$ to $98 \%$ in isolated coarctation, from $62 \%$ to $94 \%$ for associated ventricular septal defect, and from $15 \%$ to $60 \%$ for associated complex cardiac anomalies. ${ }^{4,6}$ The actuarial survival probabilities we present for patients with associated complex cardiac anomalies are remarkably high. Different strategies have been advocated to reduce mortality in this group. Our mainstream strategy for coarctation with associated cardiac lesions has been the 2-stage repair, with primary correction of the coarctation in 77 (83\%) of 93 patients in groups 2 and 3.Sixteen of (17\%) 93 patients were managed by means of 1 -stage repair in these groups. Because the 1-stage repair was reported to be a safe and effective approach in the preceding decade, ${ }^{4}$ we introduced it experimentally at the end of the study period. However, we did not abandon the 2 -stage repair because the 1-stage repair has not clearly been proved to be favorable. ${ }^{7}$

\section{Recoarctation and Late Hypertension}

Echocardiography played a central role in the screening for recoarctation of our patients. When optimal imaging is feasible, being the case in infants and children, the literature supports combined 2-dimensional and Doppler color flow echocardiography to image the aortic arch, isthmus, and coarctation site. A sensitivity of $100 \%$ for recoarctation can thus be achieved by means of echocardiography and clinical visit, as was pointed out by Therrien and colleagues. ${ }^{8}$ The primary focus in this and most other studies investigating risk factors for recurrent arch obstruction after early coarc- 
tation repair is the relationship between the technique of repair and recoarctation. The type of surgical repair might influence the prevalence of residual or recurrent coarctation by incomplete resection of ductal tissue, suture material, and the width of the anastomosis. The possible mechanisms in the process of recoarctation related to these surgical factors consist of inadequate growth of the anastomosis, active fibrosis and narrowing at the anastomotic site, thrombosis at the suture line, and retention of abnormal, possibly ductal, tissue. ${ }^{9}$ In the absence of a large randomized study, superiority of one technique over another is less likely to be demonstrated. On the whole, these studies demonstrate no difference in recoarctation incidence between RETE and subclavian flap, ${ }^{5,6}$ although the probability of recoarctation appears to be higher after simple patch aortoplasty, when patch material used was Dacron or unspecified. ${ }^{7}{ }^{10}$ Reported recoarctation rates after PTFE patch aortoplasty, although sparse, are comparable with those after other techniques. ${ }^{2,11-13}$ Although more recoarctation after patch aortoplasty has been found in this series (30 [25\%] of 118 patients vs 19 [14\%] of 133 patients for RETE), type of repair was no independent predictor for recoarctation. Furthermore, significant differences could not be established in stratifying patients younger and older than 1 month of age, although a younger age has been suggested to predispose to recoarctation after PTFE patch repair. ${ }^{2}$ The age at operation has been found to be related to the development of recoarctation and, in an inverse manner, to the development of late hypertension. Brouwer and associates ${ }^{14}$ determined the optimal age for elective aortic coarctation repair for the infant with isolated aortic coarctation who is symptom free to be 1.5 years. The risk for recoarctation decreases rapidly and levels off at 1.5 years of age, and the risk for late hypertension and premature death increases progressively after that age range. ${ }^{14,15}$ It has been pointed out that the age of 1.5 years might be rather conservative because recoarctation rates decrease to less than 5\% in current surgical experience with repair performed at age less than 1 year $^{16}$, and chronic hypertension develops in as much as $60 \%$ of patients thereafter in other studies. ${ }^{17} \mathrm{We}$ therefore stratified patients younger and older than 1 year of age but could not find any significant difference in those age groups regarding late hypertension. Nevertheless, this difference was found for type of repair because patch aortoplasty was associated with a higher late hypertension rate. We hypothesize that in patch aortoplasty the combination of residual ductal tissue and diminished aortic wall compliance is responsible for the occurrence of late hypertension in this group. These phenomena might play a role in recoarctation in long-term follow-up also. This might explain the disproportional hazards for recoarctation that were found after 5 years in patients undergoing after different types of repair (Figure 2).

\section{Arch Hypoplasia}

Several reports demonstrated that the anatomy of the aortic arch was a predictor of reintervention for recurrent obstruction after repair. ${ }^{9,14}$ Transverse arch hypoplasia was present in $32(13 \%)$ of 255 patients in this study and was demonstrated to be an independent risk factor for recoarctation. The presence of a hypoplastic arch usually increases the left ventricular obstruction created by the coarctation. Nevertheless, a conservative approach toward the hypoplastic arch seems to be justified in most cases because Siewers and associates ${ }^{18}$ have suggested that when the ratio of transverse aortic arch to ascending aorta exceeds 0.25 , the arch can be expected to grow normally without obstruction and that extended resections should be reserved for those with ratios of less than 0.25 .

\section{Aneurysm Formation}

The interval to aneurysm formation varied from 2 to almost 19 years, thereby warranting a follow-up for a long enough period. The follow-up protocol for patients in this series, including clinical visits, echocardiography and chest radiography as a screening test and performing magnetic resonance imaging on patients with positive results, was identified as an appropriate strategy in adult patients for both aneurysm formation and recoarctation by Therrien and colleagues. ${ }^{8}$ Because we consider echocardiography more sensitive and specific at lower patient ages, we believe that this policy is appropriate for children as well.

RETE proved to be superior to PTFE patch aortoplasty most apparently in respect to aneurysm formation. All aneurysm formation in this series, in $8(6.4 \%)$ of 125 patients, was encountered after patch aortoplasty. We suggest that indication for PTFE patch aortoplasty, despite its relative easy performance and favorable surgical record, must be narrowed in favor of RETE. Aneurysm formation after patch aortoplasty has been reported on extensively, with the reported incidence varying between $2 \%$ and $51 \%$. $^{1,19,20}$ The cause of aneurysm formation after patch aortoplasty has been attributed to several different factors that are discussed subsequently.

Material. There appears to be a striking difference between patch aortoplasty using Dacron grafts compared with using PTFE. Considerable foreign body giant-cell infiltration is demonstrated in Dacron grafts, ${ }^{21}$ which is not the case with PTFE. ${ }^{19}$ Probably this inflammatory response to a Dacron patch makes it more susceptible to aneurysm formation than a PTFE patch, despite Dacron being 20\% more compliant, a condition that was considered to be favorable. ${ }^{19,22,23}$ The stretching and degeneration of fibers of Dacron, with subsequent dilatation of the material, ${ }^{24}$ has not been found in PTFE, which does not appear to show any signs of breakdown through chemical or biologic processes over time. ${ }^{25}$ Indeed, a higher incidence of aneurysm forma- 
tion has been reported after Dacron patch aortoplasty than after repair with PTFE in studies in which both materials were applied. ${ }^{13,26}$ Additionally, no aneurysm formation has been encountered in several reports on use of PTFE ${ }^{2,12,13}$ compared with aneurysm rates of between $3 \%$ to $22 \%$ after patch aortoplasty with Dacron patch. ${ }^{20,22,23}$ As regards the use of nonprosthetic material, observations are sparse. Autogenous internal thoracic artery was applied as patch material in several studies, with good results in limited follow-up periods. ${ }^{27}$

Resection of coarctation ridge. The coarctation ridge was excised in the performance of patch aortoplasty in all our patients until 1991. At that time, we changed our policy with regard to resecting the coarctation ridge because violating the intimal aortic layer by resection of the fibrous coarctation membrane has been found to be highly related to aneurysm formation in patients in several studies. ${ }^{22,23}$ DeSanto and associates ${ }^{28}$ performed patch aortoplasty with and without concomitant intimal excision in dogs experimentally. Aneurysms formed in 8 of 12 animals who had intimal excisions, and no aneurysms formed in the control animals. All true aneurysm formation we observed might be caused by ridge resection in patients before the recent era. With a modified patch technique, leaving the coarctation ridge intact, we only encountered one false aneurysm. These observations correspond with those of Backer and coworkers. $^{2}$

Strain and stress. The experimental in vitro findings of Smaill and associates ${ }^{29}$ suggest that synthetic patch aortoplasty might produce increases in wall strain and disproportionate increases in stress adjacent to the patch associated with changes in local aortic wall geometry that are a direct result of patch implantation. The altered hemodynamics that result form the different tensile strengths of a Dacron patch and the posterior aortic wall, with the pulsatile waveform being completely directed to the posterior aortic wall by the inflexible anterior patch, might cause dilatation of the pliable aortic wall. ${ }^{20,22,23}$ We do not know of any report on PTFE patch material or modification of the technique of patch aortoplasty in which these effects were found to be successfully prevented.

Age. None of the age categories were found to be risk factors for aneurysm formation in our series. On the contrary, previous reports on Dacron patch aortoplasty supported early surgical repair. ${ }^{1,15}$ The risk of aneurysm formation was reduced substantially by operating earlier. ${ }^{1}$ Although the aortic wall might be structurally different in infants, thus enabling it to adapt more rapidly to a patch aortoplasty than the aortic wall of patients who undergo surgical repair at an older age, this might depend on Dacron. According to several authors, prosthetic patch aortoplasty should be abandoned in adolescents and adults, in whom a high incidence of aneurysm formation was found with ad- vanced age. Tubular interpositioning grafting and patch aortoplasty with the autogenous arterial wall are proposed as viable alternatives. ${ }^{13,20,27}$ However, there appears to be a minimum age because Backer and associates ${ }^{2}$ found a high recurrence rate in infants younger than 1 month of age, whereas the recoarctation rate was 4 of 97 in patients older than 1 month of age after patch aortoplasty with PTFE.

Aortic arch hypoplasia. Different from recoarctation, arch hypoplasia did not reach statistical significance as a risk factor for aneurysm formation. In contrast to our findings, Bogaert and associates ${ }^{30}$ have identified transverse arch hypoplasia as a condition highly related to aneurysm formation after patch aortoplasty. They suggest that narrowing of an aortic segment leads to blood flow acceleration and poststenotic turbulence, which might induce aneurysm development in the distal aortic segments. Because aneurysm formation has been encountered after RETE, ${ }^{11}$ in which the coarctated segment is fully resected, and no abnormal patch material is present, wall abnormalities by themselves cannot be (solely) responsible for aneurysm formation, despite statements in several reports. ${ }^{11,20,28} \mathrm{Ab}$ normal flow patterns originating in a concomitant hypoplastic arch might have a similar influence on RETE and patch aortoplasty. ${ }^{30}$

\section{Limitations}

The design of this study is limited by the fact that it is retrospective and spans 3 decades. During this period, including patients for RETE and patch aortoplasty has been rather constant. However, both surgical techniques have been improved gradually in the course of time, although era (1971-1987 vs 1988-2000) was not related to any outcome. Furthermore, patients were not randomized for both techniques. The choice of either RETE or patch aortoplasty was based on the surgeon's preference in general, but selection bias could not be ruled out in this study design.

\section{Conclusions}

The present study findings do not allow extensive conclusions to be drawn in the treatment of coarctation associated with complex intracardiac malformations, for which this association was the most important risk factor. Comparing both surgical techniques, the resection of the coarctation ridge seems to be an important factor with regard to aneurysm formation. Considerable aneurysm formation was found after patch aortoplasty combined with coarctation ridge resection. Our findings demonstrate no differences between recoarctation and aneurysm formation with a modified patch aortoplasty. Arch hypoplasia and age younger than 1 month must be considered to predispose to recoarctation in patients with coarctation managed surgically. Although a slightly increased risk of late hypertension was 
identified after patch repair, we consider both surgical techniques to be comparable.

We thank Ingeborg van der Tweel for her contribution to the statistical analysis.

\section{References}

1. Parks WJ, Ngo TD, Plauth WH Jr, et al. Incidence of aneurysm formation after Dacron patch aortoplasty repair for coarctation of the aorta: long-term results and assessment utilizing magnetic resonance angiography with three-dimensional surface rendering. $J$ Am Coll Cardiol. 1995;26(1):266-71.

2. Backer CL, Paape K, Zales VR, Weigel TJ, Mavroudis C. Coarctation of the aorta. Repair with polytetrafluoroethylene patch aortoplasty. Circulation. 1995;92(suppl 9):II132-6.

3. Backer CL, Mavroudis C. Congenital Heart Surgery Nomenclature and Database Project: patent ductus arteriosus, coarctation of the aorta, interrupted aortic arch. Ann Thorac Surg.. 2000;69(suppl 4):S298-307.

4. Conte S, Lacour-Gayet F, Serraf A, et al. Surgical management of neonatal coarctation. J Thorac Cardiovasc Surg. 1995;109(4):663-75.

5. Knott-Craig CJ, Elkins RC, Ward KE, et al. Neonatal coarctation repair. Influence of technique on late results. Circulation. 1993; 88(suppl):II198-204.

6. Ziemer G, Jonas RA, Perry SB, Freed MD, Castaneda AR. Surgery for coarctation of the aorta in the neonate. Circulation. 1986;74(suppl): I25-31.

7. Quaegebeur JM, Jonas RA, Weinberg AD, Blackstone EH, Kirklin JW. Outcomes in seriously ill neonates with coarctation of the aorta. A multiinstitutional study. J Thorac Cardiovasc Surg. 1994;108(5):84154.

8. Therrien J, Thorne SA, Wright A, Kilner PJ, Somerville J. Repaired coarctation: a "cost-effective" approach to identify complications in adults. J Am Coll Cardiol. 2000;35(4):997-1002.

9. Kappetein AP, Zwinderman AH, Bogers AJ, Rohmer J, Huysmans HA. More than thirty-five years of coarctation repair. An unexpected high relapse rate. J Thorac Cardiovasc Surg. 1994;107(1):87-95.

10. Zehr KJ, Gillinov AM, Redmond JM, et al. Repair of coarctation of the aorta in neonates and infants: a thirty-year experience. Ann Thorac Surg. 1995;59(1):33-41.

11. Aebert H, Laas J, Bednarski P, Koch U, Prokop M, Borst HG. High incidence of aneurysm formation following patch plasty repair of coarctation. Eur J Cardiothorac Surg. 1993;7:200-5.

12. Sade RM, Crawford FA, Hohn AR, Riopel DA, Taylor AB. Growth of the aorta after prosthetic patch aortoplasty for coarctation in infants. Ann Thorac Surg. 1984;38:21-5.

13. Yee ES, Soifer SJ, Turley K, Verrier ED, Fishman NH, Ebert PA. Infant coarctation: a spectrum in clinical presentation and treatment. Ann Thorac Surg. 1986;42:488-93.

14. Brouwer RM, Erasmus ME, Ebels T, Eijgelaar A. Influence of age on survival, late hypertension, and recoarctation in elective aortic coarctation repair. Including long-term results after elective aortic coarcta- tion repair with a follow-up from 25 to 44 years. J Thorac Cardiovasc Surg. 1994;108(3):525-31.

15. Cohen M, Fuster V, Steele PM, Driscoll D, McGoon DC. Coarctation of the aorta. Long-term follow-up and prediction of outcome after surgical correction. Circulation. 1989;80(4):840-5.

16. Seirafi PA, Warner KG, Geggel RL, Payne DD, Cleveland RJ. Repair of coarctation of the aorta during infancy minimizes the risk of late hypertension. Ann Thorac Surg. 1998;66(4):1378-82.

17. van Son JA. Repair of coarctation of the aorta. Ann Thorac Surg. 1999;67(4):1212-3.

18. Siewers RD, Ettedgui J, Pahl E, Tallman T, del Nido PJ. Coarctation and hypoplasia of the aortic arch: will the arch grow? Ann Thorac Surg. 1991;52:608-14.

19. Bromberg BI, Beekman RH, Rocchini AP, et al. Aortic aneurysm after patch aortoplasty repair of coarctation: a prospective analysis of prevalence, screening tests and risks. J Am Coll Cardiol. 1989;14(3):73441.

20. Ala-Kulju K, Heikkinen L. Aneurysm after patch graft aortoplasty for coarctation of the aorta: long-term results of surgical management. Ann Thorac Surg. 1989;47:853-6.

21. Heikkinen L, Sariola H, Salo J, Ala-Kulju K. Morphological and histopathological aspects of aneurysms after patch aortoplasty for coarctation. Ann Thorac Surg. 1990;50:946-8.

22. Clarkson PM, Brandt PWT, Barratt-Boyes BG, Rutherford JD, Kerr AR, Neutze JM. Prosthetic repair of coarctation of the aorta with particular reference to Dacron onlay patch grafts and late aneurysm formation. Am J Cardiol. 1985;56:342-6.

23. Rheuban KS, Gutgesell HP, Carpenter MA, et al. Aortic aneurysm after patch angioplasty for aortic isthmic coarctation in childhood. Am J Cardiol. 1986;58:178-80.

24. Watanabe T, Kusaba A, Kuma H, Kina M, Okadome K, Inokuchi K. Failure of Dacron arterial prostheses caused by structural defects. J Cardiovasc Surg. 1983;24:95-100.

25. Boyce B. Physical characteristics of expanded polytetrafluoroethylene grafts. In: Stanley JC, editor. Biological and synthetic vascular prostheses. New York: Grune \& Stratton; 1982.

26. Malan JE, Benatar A, Levin SE. Long-term follow-up of coarctation of the aorta repaired by patch angioplasty. Int J Cardiol. 1991;30(1):2332.

27. Owens WA, Tolan MJ, Cleland J. Late results of patch repair of coarctation of the aorta in adults using autogenous arterial wall. Ann Thorac Surg. 1997;64(4):1072-4.

28. DeSanto A, Bills RG, King H, Waller B, Brown JW. Pathogenesis of aneurysm formation opposite prosthetic patches used for coarctation repair. J Thorac Cardiovasc Surg. 1987;94:720-3.

29. Smaill BH, McGiffin DC, Legrice IJ, Young AA, Hunter PJ, Galbraith AJ. The effect of synthetic patch repair of coarctation on regional deformation of the aortic wall. J Thorac Cardiovasc Surg. 2000; 120(6):1053-63.

30. Bogaert J, Gewillig M, Rademakers F, et al. Transverse arch hypoplasia predisposes to aneurysm formation at the repair site after patch angioplasty for coarctation of the aorta. J Am Coll Cardiol. 1995; 26(2):521-7. 